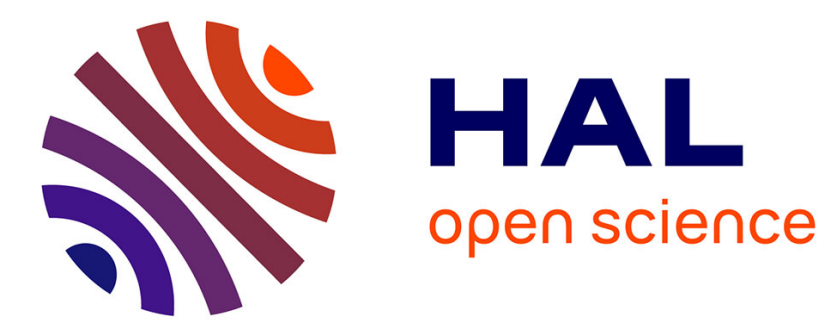

\title{
Analytical solution incorporating history-dependent processes for quick assessment of capillary trapping during $\mathrm{CO} 2$ geological storage
}

\author{
Jean-Charles Manceau, Jeremy Rohmer
}

\section{- To cite this version:}

Jean-Charles Manceau, Jeremy Rohmer. Analytical solution incorporating history-dependent processes for quick assessment of capillary trapping during CO2 geological storage. Transport in Porous Media, 2011, 90, pp.721-740. 10.1007/s11242-011-9812-z . hal-00617545

HAL Id: hal-00617545

https: / hal-brgm.archives-ouvertes.fr/hal-00617545

Submitted on 29 Aug 2011

HAL is a multi-disciplinary open access archive for the deposit and dissemination of scientific research documents, whether they are published or not. The documents may come from teaching and research institutions in France or abroad, or from public or private research centers.
L'archive ouverte pluridisciplinaire HAL, est destinée au dépôt et à la diffusion de documents scientifiques de niveau recherche, publiés ou non, émanant des établissements d'enseignement et de recherche français ou étrangers, des laboratoires publics ou privés. 


\title{
Analytical solution incorporating history- dependent processes for quick assessment of capillary trapping during $\mathrm{CO}_{2}$ geological storage
}

\author{
Jean-Charles Manceau, Jérémy Rohmer
}

BRGM, 3 avenue C. Guillemin 45060 ORLEANS Cedex 2, France

+33238644805

+33238643689

jc.manceau@brgm.fr

www.brgm.fr

Carbon storage in saline formations is considered as a promising option to ensure the necessary decrease of $\mathrm{CO}_{2}$ anthropogenic emissions. Its industrial development in those formations is above all conditioned by its safety demonstration. Assessing the evolution of trapped and mobile $\mathrm{CO}_{2}$ across time is essential in the perspective of reducing leakage risks. In this work, we focus on residual trapping phenomenon occurring during the wetting of the injected $\mathrm{CO}_{2}$ plume. History dependent effects are of first importance when dealing with capillary trapping. We then apply the classical fractional flow theory (Buckley-Leverett type model) and include trapping and hysteresis models; we derive an analytical solution for the temporal evolution of saturation profile and of $\mathrm{CO}_{2}$ trapped quantity when injecting water after the gas injection ("artificial imbibition"). The comparison to numerical simulations for different configurations shows satisfactory match and justifies, in the case of industrial $\mathrm{CO}_{2}$ storage, the assumptions of incompressible flow with no consideration of capillary pressure. The obtained analytical solution allows the quick assessment of both the quantity and the location of mobile gas left during imbibition.

$\mathrm{CO}_{2}$ geological storage, safety, quick assessment, residual trapping, hysteresis 


\section{Introduction}

In addition to non-emitting and renewable energy production among others, carbon dioxide capture and storage (CCS) is considered as a promising option to ensure the necessary decrease of $\mathrm{CO}_{2}$ anthropogenic emissions (IPCC 2005). Regarding the storage capacity needed to develop geological sequestration at a large scale, saline aquifers offer good potentials (Bachu 2002). Its industrial development in those formations is above all conditioned by its safety demonstration (IEAGHG 2007). A comprehensive strategy should then be adopted, made up of a risk assessment, a monitoring plan and corrective measures plan as stated by the European Directive on the geological storage of carbon dioxide (EC 2009).

Several modes of trapping take part in the confinement within saline aquifers: as a gas phase, the buoyant $\mathrm{CO}_{2}$ can be trapped below an impermeable cap rock layer (structural trapping, e.g. Bachu et al. 1994) or disconnected from the main cluster and immobilized due to capillary forces (capillary or residual trapping, e.g. Juanes et al. 2006); dissolved in brine, it can be trapped in the aqueous phase (solubility trapping, e.g. Ennis-King and Paterson 2005) before reacting with rocks and precipitating (mineral trapping, e.g. Bachu et al. 1994; Gunter et al. 1997). These trapping mechanisms occur under specific conditions (notably geological, hydraulic and chemical) and over different time scales. Structural trapping alone is not sufficient to prevent migration of $\mathrm{CO}_{2}$ in case of cap-rock anomaly for instance (Nghiem et al. 2009). The evaluation of safer modes (residual, solubility and mineral trapping) is then essential; this study is focused on residual trapping as it has been shown as the fastest mode of trapping (e.g. Qi et al. 2009; Juanes et al. 2010).

When injecting supercritical $\mathrm{CO}_{2}$ (gas-like since it is less dense and viscous than the native brine - we use the term gas in the following) into saline aquifers (liquid phase), the native brine is drained by $\mathrm{CO}_{2}$ (the liquid saturation decreases). The formation minerals being naturally water-wet, the liquid phase can be considered as the wetting fluid (Juanes et al. 2005). When the injection stops, according to the driving forces, some parts of the initial plume will experience a wetting stage (gas saturation decreases) while others will continue being in drainage stage. Wetting (also called imbibition) may either occur naturally in response to regional 
groundwater flow or to gravity currents (i.e. "natural" imbibition), or artificially in response to liquid injection through wells in depth (i.e. "artificial" imbibition). Artificial imbibition aims at increasing the storage efficiency (e.g. Qi et al. 2009) or at forcing the immobilization of the injected $\mathrm{CO}_{2}$ in case of significant "irregularities" detected at the reservoir level (Manceau et al. 2010) or at the level of a potentially impacted groundwater aquifer (Esposito and Benson 2010). When imbibition occurs, the gas saturation decreases until a residual gas saturation that corresponds to the amount of gas that is capillary trapped and hence immobilized. This Darcy's scale observation is explained (e.g. by Lenormand et al. 1983; Suicmez et al. 2008) by the displacement phenomena governing the interactions between the wetting and non-wetting phase at pore scale (i.e. piston-like displacement, cooperative pore-body filling and snap-off). These phenomena lead to the immobilization of the wetting liquid during drainage (through by-passing) and of the non-wetting gas (through by-passing and snapoff) explaining the residual trapping observed. The trapped fraction depends on the initial saturation since, for instance, when the non-wetting phase initial concentration is lower, the number of potential sites where snap-off can occur is lower as well.

Moreover, a contact angle hysteresis modification between drainage and imbibition occurs due to the surface roughness and due to the wettability change once the non-wetting phase has been introduced (Valvatne 2004; de Gennes et al. 2004). This hysteresis effect is taken into account at Darcy's scale with the dependence of the characteristic curves describing the two-phase flow (i.e. evolution of the relative permeability and capillary pressure functions) on the saturation history. In order to measure supercritical $\mathrm{CO}_{2}-$ brine characteristic curves, several experimental technics exist as the steady and unsteady state usual approaches. However, the specificities of the $\mathrm{CO}_{2}$ (notably the reactivity with rock) and of the reservoir rock (types and heterogeneity) as well as the large range of pressure-temperature conditions that have to be tested make difficult the full interpretation of the measurements (Müller, 2011). Hence, the hysteresis phenomenon as well as its amplitude still remains little known in the field of geological $\mathrm{CO}_{2}$ storage. 
Capillary trapping assessment is essential in a safety management perspective. Aiming either at evaluating the plume behaviour under a natural groundwater flow or designing the injection parameters (e.g. rate, injection period) in order to create an "artificial imbibition", an estimation of the temporal trapped gas quantity evolution and of the spatial distribution of gas saturation (mobile and immobile) is of first importance.

In the present paper, we develop in this purpose an analytical solution applying the classical fractional flow theory, and including trapping and hysteresis models to incorporate history dependant processes. In this study, we focus on the "artificial" imbibition case.

\section{Review of existing models}

By its very objective, the developed solution should describe the evolution of the gas plume as well as the residual trapping that occurs as soon as brine is injected. Both phenomena are described through different kinds of models from which our solution is derived. In this matter, we present a brief overview of the existing models.

\subsection{Trapping and hysteresis models}

Multi-phase flow modelling implies the use of characteristic curves describing, at Darcy's scale, the interactions between the different phases. They represent the evolutions of both capillary pressure and relative permeabilities (associated to the wetting and the non-wetting phase). In a first approach, the capillary pressure and relative permeabilities are functions of one phase saturation only (e.g. van Genuchten 1980; Brooks \& Corey 1966).

However these models fail in representing the hysteretic phenomena explained in the previous section. In this view, the trapped fraction should be determined at first (with a trapping model) and, subsequently, the history-dependent relative permeabilities and capillary pressure functions should be assessed as a function of the saturation, of the trapped fraction and of the process in progress (with a hysteresis model). Please note that the trapped wetting phase fraction is commonly considered constant. As an illustration of the hysteresis model, Figure 
1 depicts the evolution of the gas relative permeability during drainage and wetting processes.

One of the most classic non-wetting phase trapping models is Land's model (1968). This model being only suitable for water-wet media, Spiteri et al. (2008) developed a new model for other wettablilities. Several hysteresis models have been built based on Land's trapping model, amongst whom are Carlson's (1981), and Parker and Lenhard's (Parker and Lenhard 1987; Lenhard and Parker 1987). They are based on classical non-hysteretic relative permeability and capillary pressure models and give the characteristic curves during drainage and wetting (for the primary drainage-imbibition cycle and for the following cycles).

[Fig.1]

\subsection{Models describing gas plume dynamics}

Safety (e.g. leakage concerns) and performance (e.g. injectivity issues) assessments in the field of $\mathrm{CO}_{2}$ geological storage notably require plume extension models. Many analytical and numerical models have been developed, based on existing fluid mechanics theories. Analytical models allow quick and flexible computations while numerical models allow dealing with the complexity of the phenomena.

Two main families have emerged among analytical and semi-analytical models aiming at characterizing the evolution of one phase in another one (Dentz and Tartakovsky 2009). The first approach studies the shape of one phase plume assuming a marked delimitation between the two phases that do not mixed (at Darcy's scale sense) while the second is focused on the evolution of one phase in terms of its saturation profile.

The first family of models (called here sharp interface models) are based on the so-called sharp interface approximation stipulating that the $\mathrm{CO}_{2}$ saturation gradient thickness is low compared to the distances concerned. Capillary forces are neglected in these models. After Bear's work (1972), some expressions have been derived specifically for $\mathrm{CO}_{2}$ sequestration in deep saline aquifers, first for the injection period when gravity forces can be neglected (Nordbotten et al. 2005; Nordbotten and Celia 2006) and then for post-injection period (with gravity forces) (Hesse et al. 2007). While these works were carried out for horizontal and 
undisturbed aquifers, others studied the effects of sloppy formations (Hesse et al. 2006) and of groundwater flow (Juanes and MacMinn 2008; Juanes et al. 2010; MacMinn et al. 2010). Some of the previously cited works (Hesse et al. 2006; Juanes and MacMinn 2008; Juanes et al. 2010; MacMinn et al. 2010) also included capillary trapping after imbibition following Kochina et al. (1983). However, these models assumed a constant residual gas saturation after wetting, hence neglecting the history-dependent processes.

The second family of models (named here Buckley-Leverett models) uses the fractional flow theory and is based on Buckley-Leverett equation (Buckley and Leverett 1942) that, neglecting gravity and capillary pressure, allows finding a solution for saturation variability. Concerning $\mathrm{CO}_{2}$ geological sequestration, Noh et al. (2007) and Zeidouni et al. (2009) used this approach to model drainage occurring during injection. They took into account solubility and partitioning of the several components $\left(\mathrm{CO}_{2}\right.$, water) into both phases; Noh et al. (2007) also considered capillary trapping during wetting with a constant residual gas saturation.

These two kinds of models are very similar since the underlying theory is alike. The governing equation comes from continuity and Darcy's equations. In the sharp interface models, the purpose is to estimate the shape of the gas plume. The sharp interface and the vertical equilibrium (or Dupuit) approximations are made so that the gas saturation can be replaced by the height of gas (interface height). The capillary pressure, which is neglected in the Buckley-Leverett models, is replaced, in the sharp interface models, by a "pseudo-capillary" pressure (Gasda et al. 2009), which is the difference of both phases fluid-static pressures. Practically, the additional approximations made in the sharp-interface models allow using the Buckley-Leverett models in two dimensions (Yortsos 1995).

In this paper, we propose a solution for the gas plume evolution taking into account variable residual gas saturation. As described by the existing trapping models, this value is highly influenced by the gas saturation reached before imbibition. Moreover, these history-dependent effects have been shown to be significant (this was numerically demonstrated for instance by Doughty 2007). Therefore, in our study, we prefer Buckley-Leverett models to the sharp interface ones since the saturation variability is of first importance. A similar choice has 
been made by Furati (1997), followed by van Kats and van Duijn (2001), who studied the effects of relative permeabilities hysteresis.

\section{Mathematical model}

The model should enable the representation of a $\mathrm{CO}_{2}$ injection (at a constant rate $Q_{g}$ ) followed by a forced imbibition (at a constant rate $Q_{l}$ ) and the associated saturation variations in terms of trapped and mobile gas (see the conceptual layout on Figure 2). We focus on the artificial brine injection and use a 1D radially symmetric geometry.

[Fig.2]

We apply the fractional flow theory (Buckley and Leverett 1942), considering the flow incompressible and immiscible.

The continuity equation gives:

$$
\text { (1) } \frac{\partial S_{g}}{\partial t}+\frac{Q_{i n j}}{\pi h \varphi} \frac{\partial f_{g}}{\partial r^{2}}=0 \text {, }
$$

where $f_{g}=\frac{q_{g}}{q_{\text {tot }}}$ is the fraction of gas in the total flowing stream. Note that $q_{\text {tot }}=Q_{i n j}, Q_{i n j}$ being the volume injection rate (constant over the $\mathrm{CO}_{2}$ and brine injection periods, but possibly different).

Developing $f_{g}$ with Darcy's equation and neglecting gravity (1D horizontal model) and capillary pressure, we obtain:

$$
\text { (2) } f_{g}=\frac{q_{g}}{q_{g}+q_{l}}=\frac{1}{1+\frac{\lambda_{l}}{\lambda_{g}}}
$$

with the mobility $\lambda_{i}=\frac{k_{r e l i}}{\mu_{i}} . f_{g}$ is then dependent on the saturation only (and on the history), which allows writing:

$$
\text { (3) } \frac{\partial S_{g}}{\partial t}+\frac{Q_{i n j}}{\pi h \varphi} \frac{d f_{g}}{d S_{g}} \frac{\partial S_{g}}{\partial r^{2}}=0 \text {. }
$$

We scale equation (3) for the gas injection period and note $T_{i n j}$ the injection time at $Q_{g}$ rate and $r_{0}$ the radius of the cylinder with a height $h$ and porosity $\varphi$ containing the volume of gas injected during $T_{i n j}$ and we choose: $\tau=\frac{t}{T_{i n j}}$ and $\xi=\frac{r}{r_{0}}$. 
The governing equation for the gas injection period gets simpler:

$$
\text { (4) } \frac{\partial s_{g}}{\partial \tau}+\frac{d f_{g}}{d S_{g}} \frac{\partial S_{g}}{\partial \xi^{2}}=0
$$

For the brine injection period, i.e. $t \geq T_{\text {inj }}$, we decide:

$$
\tau=1+\frac{Q_{g}}{Q_{l}} \frac{t-T_{i n j}}{T_{i n j}}
$$

This arbitrary choice leads to the same governing equation for both injection periods. The reformulation of the equation (4) leads to the so-called BuckleyLeverett equation:

$$
\text { (6) } \quad\left(\frac{\partial \xi^{2}}{\partial \tau}\right)_{S_{g}}=\frac{d f_{g}}{d s_{g}}
$$

Classically, $\zeta=\frac{\xi^{2}}{\tau}$ denotes the similarity variable, i.e. the suitable combination of primary variables corresponding to the velocity of the waves, which are solutions of the conservation law (see e.g. Lax 1972). In other words, the equation (6) states that the increasing rate of the "dimensionless area" $\xi^{2}$ (in this case of an axisymmetric geometry) swept over by a specified saturation is given by $\frac{d f_{g}}{d s_{g}}$, i.e. by the variations of the gas fractional flow when saturation changes. Then, the Buckley-Leverett equation naturally implies studying fractional flow function. As mentioned previously, the fractional flow is a function of the dynamic viscosities, which can be taken constant under the incompressible, immiscible and isothermal flow assumptions and of the relative permeabilities that depends on the saturation as well as on the history of the saturation evolutions. Because of hysteresis effects, separated works are done according to the flow process occurring (drainage or imbibition).

\subsection{Phase I: gas injection}

When injecting gas in native brine, both liquid and gas permeabilities will follow the so-called primary drainage curve (that depends on the model chosen). The flow function is generally considered as S-shaped in literature (e.g. Furati 1997 and Medeiros et al. 1998), i.e. convex on part of the saturation interval and concave on the complementary one. It implies a physical impossibility in Buckley-Leverett equation, the derivative of the flux function having the same 
value for two different saturations. The problem can nevertheless be solved by means of a shock, thus introducing a discontinuity in the saturation profile (Buckley and Leverett 1942). This multivalued situation is due to the no-capillary pressure approximation. The discontinuity must satisfy the jump condition (Lax 1972; Smoller 1994). This gives the velocity of the shock (denoted shockI):

$$
\zeta_{\text {shockI }}=\frac{f_{g, \text { drainage }}\left(S_{g, \text { shockI }}^{-}\right)-f_{g, \text { drainage }}\left(S_{g, \text { shockI }}^{+}\right)}{S_{g, \text { shockI }}^{-}-S_{g, \text { shockI }}^{+}}
$$

Where - and + refer to downstream and upstream of shockI. Note that $f_{g, \text { drainage }}\left(S_{g, \text { shockI }}^{+}\right)$and $S_{g, \text { chockI }}^{+}$are equal to zero (downstream of the advancing gas front, only native brine is present).

Welge (1952) sets-up a practical and graphical technique to find out the shock saturation as well as its velocity. As a matter of fact, the discontinuity (or advancing gas front) saturation can then be retrieved graphically plotting the line passing through the origin and tangent to the fractional flow curve; the front velocity is its slope. The rest of the gas saturation profile, obtained through Buckley-Leverett equation, then starts, at the vicinity of the injection point, from the residual liquid saturation and decreases progressively to reach the saturation front saturation.

\subsection{Phase II: Brine injection}

When injecting brine, the gas saturation decreases and one moves along the fractional flow curve in the opposite direction than for phase I. However, this function is different from the drainage one, since the relative permeability curves are prone to hysteresis effects.

The problem is the same though, since the curve is still S-shape meaning that a saturation discontinuity will occur at the leading edge of the injected brine, with a velocity given by the Rankine-Hugoniot condition. Contrary to the previous phase, gas is still present and flows upward as well as downward of the imbibition front. Moreover, the saturation on both sides of this front evolves over time: downward to the front, drainage is still going on and the saturation can be obtained by means of the drainage fractional flow curves; wetting is occurring upward and the saturation is obtained through imbibition fractional flow curves. Please note that the imbibition fractional curves depend on the saturation reached 
when the flow reversal occurs (corresponding to the downward saturation), which means that the velocity of the imbibition front depends on the reversal flow saturation as well:

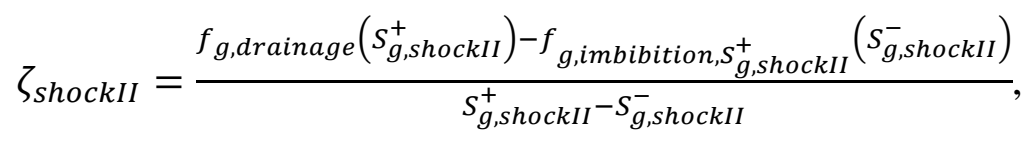

where $f_{\text {g,imbibition, } S_{g, \text { shockII }}^{+}}$corresponds to the imbibition gas fractional flow function associated to a reversal saturation equal to $S_{g, \text { shockII }}^{+}$. This expression is clearly complex, as infinity of such imbibition gas fractional flow curves have to be computed to solve the entire problem.

We therefore decide to introduce the following approximation $S_{g, \text { shockII }}^{-}=$ $S_{g r}\left(S_{g, \text { shockII }}^{+}\right)$; we call it the "instantaneous trapping" approximation since we consider that, as soon as the imbibition front reaches a specific saturation, a jump towards the associated residual saturation is instantaneously done. Please note that this assumption is conservative in that the front velocity obtained is lower. This choice leads to:

$$
\zeta_{\text {shockII }}=\frac{f_{g, \text { drainage }}\left(S_{g, \text { shockII }}^{+}\right)-f_{g, \text { imbibition }, S_{g, \text { shockII }}^{+}}\left[S_{g r}\left(S_{g, \text { chocII }}^{+}\right)\right]}{S_{g, \text { shockII }}^{+}-S_{g r}\left(S_{g, \text { chocII }}^{+}\right)}
$$

By definition, $f_{g, \text { imbibition, } S_{g, \text { shockII }}^{+}}\left[S_{g r}\left(S_{g, \text { chocII }}^{+}\right)\right]=0 . \zeta_{\text {shockII }}$ is then independent of the imbibition curves which considerably simplifies the problem. This assumption is justified by the following reasoning. Gas fractional flow function depends on mobility ratio $\left(\lambda_{l} / \lambda_{g}\right)$ in that the lower this ratio, the higher the gas flow and thus the more left-shifted the inflection point of the S-shaped function. Given relative permeability functions, one can infer that the saturation interval where the gas fractional flow is convex is smaller when the viscosity ratio decreases (e.g. McWorther 1990). In the case of $\mathrm{CO}_{2}$ geological storage, gas viscosity is much lower than liquid one and the viscosity ratio is particularly low. The difference between the saturation directly downstream the imbibition front and the residual gas saturation is then likely to be slight (additional discussion on the validity of this approximation is provided in section 5.2). By introducing this assumption, it is possible to establish for each brine injection time the saturation profile that is made of the profile corresponding to the 
drainage phase downward of the advancing brine front and, upward, of the residual saturation calculated from the saturation reached by the brine advancing front at earlier time (see Figure 3 for the illustration of the elaboration methodology of the gas saturation profile).

[Fig.3]

\section{Evolution of trapped $\mathrm{CO}_{2}$ quantity during imbibition}

\subsection{Trapped $\mathrm{CO}_{2}$ quantity: solution}

Let us consider a saturation value $S$. The first step consists in determining the brine injection time $(\tau)$, at which the brine front intercepts the saturation $S$. The "dimensionless area" reached by the injected brine at $\tau$ is:

$$
\text { (10) } \xi_{\text {brine }}(\tau)^{2}=\int_{1}^{\tau} \zeta_{\text {shockII }}(t) d t
$$

The dimensionless area reached by the gas saturation $S$ at $\tau$ is:

$$
\text { (11) } \xi_{\mathrm{S}}(\tau)^{2}=\frac{d f_{g, \text { drainage }}}{d \mathrm{~S}_{g}}(\mathrm{~S}) \tau
$$

These two areas being equal,

$$
\text { (12) } \int_{1}^{\tau} \zeta_{\text {shockII }}(t) d t=\frac{d f_{g, \text { drainage }}}{d \mathrm{~S}_{g}}(\mathrm{~S}) \tau
$$

The differentiation according to $\tau$ gives:

$$
\zeta_{\text {shockII }}(\mathrm{S}) d \tau=\frac{d f_{g, \text { drainage }}}{d \mathrm{~S}_{g}}(\mathrm{~S}) d \tau+\frac{d^{2} f_{g, \text { drainage }}}{d \mathrm{~S}_{g}^{2}}(\mathrm{~S}) \tau d \mathrm{~S},
$$

which leads to the following separable equation:

$$
\text { (14) } \frac{d \tau}{\tau}=\frac{\frac{d^{2} f_{g, d r a i n a g e}}{d \mathrm{~S}_{g}^{2}}(\mathrm{~S})}{\zeta_{\text {shockII }}(\mathrm{S})-\frac{d f_{g, d r a i n a g e}}{d \mathrm{~S}_{g}}(\mathrm{~S})} d \mathrm{~S} \text {. }
$$

Integrated between 1 and a chosen time $\tau^{*}$, corresponding respectively to collision saturations $1-S_{l r}$ and $S^{*}$, we get the time at which the brine front reaches one specific saturation (here $S^{*}$ ): 


$$
\text { (15) } \tau^{*}=\tau\left(S^{*}\right)=\exp \left(\int_{1-S_{\text {lr }}}^{S^{*}} \frac{\frac{d^{2} f_{g, \text { drainage }}}{d \mathrm{~S}_{g}^{2}}(\mathrm{~S})}{\zeta_{\text {shockII }}(\mathrm{S})-\frac{d f_{g, \text { drainage }}}{d \mathrm{~S}_{g}}(\mathrm{~S})} d S\right) \text {. }
$$

Taking $S^{*}=S_{g, \text { shockI }}^{-}$, one retrieves the complete trapping dimensionless time. One can deduce the dimensionless radius at which this collision occurs:

$$
\text { (16) } \xi_{\text {collision }, S^{*}}=\xi_{S^{*}}\left(\tau^{*}\right)=\sqrt{\frac{d f_{g, \text { drainage }}}{d S_{g}}\left(S^{*}\right) \cdot \tau\left(S^{*}\right)}
$$

from which the dimensioned volume of mobile gas $V_{\text {freeg }}$ as well as the mobile gas mass fraction $f r_{\text {freeg }}$ can be inferred as a function of the saturation reached by the imbibition front:

$$
\begin{gathered}
V_{\text {freeg }}\left(S^{*}\right)=\frac{2 Q_{g} T_{\text {inj }}}{\rho_{g}} \int_{S^{*}}^{S_{g, \text { chocI }}^{-}} S \cdot \xi_{S}\left(S^{*}\right) \cdot \frac{d \xi_{S}}{d S_{g}}\left(S^{*}\right) d S \\
f_{\text {freeg }}\left(S^{*}\right)=2 \int_{S^{*}}^{S_{g, \text { chocI }}^{-}} S \cdot \xi_{S}\left(S^{*}\right) \cdot \frac{d \xi_{S}}{d S_{g}}\left(S^{*}\right) d S .
\end{gathered}
$$

Combining it with equation (15), we obtain this fraction as a function of the brine injection time.

\subsection{Results on a reference test case}

The following reference test case is considered: supercritical $\mathrm{CO}_{2}$ is injected into a $20 \mathrm{~m}$ thick and $1200 \mathrm{~m}$ depth homogeneous aquifer (initially completely saturated with native water) through a vertical injection well that fully penetrates the reservoir. Properties and initial conditions of a deep aquifer likely to be suitable for $\mathrm{CO}_{2}$ sequestration are provided in Table 1 mainly based on Pruess and Spycher paper (2007), with no salinity in our case.

\section{[Table1]}

The following scenario is considered: $\mathrm{CO}_{2}$ is injected in the storage aquifer at a rate of $250 \mathrm{kt} / \mathrm{y}$. An irreversible "abnormal behaviour" is assumed to occurr and to be detected after one year of injection (e.g. $\mathrm{CO}_{2}$ escaping from the storage aquifer). To mitigate such a risk event, the following corrective action is implemented; water is injected at a rate of $160 \mathrm{kt} / \mathrm{y}\left(44 \mathrm{~m}^{3} / \mathrm{h}\right)$ in the view to enhance and accelerate gas trapping, i.e. to immobilize $\mathrm{CO}_{2}$ by forcing the wetting process (see e.g. Manceau et al., 2010). 
Please note that we considered Land's trapping model associated to Lenhard and Parker's hysteretic relative permeability functions (Lenhard and Parker 1987).

Table 2 gives the values chosen for the trapped saturation and permeability functions computation.

\section{[Table2]}

Figure 4 depicts the analytical model results. It provides the analytical solutions for gas saturation profile after several water injection duration times and the temporal evolution of mobile gas fraction during water injection. The injected 250 kt of $\mathrm{CO}_{2}$ are completely trapped after less than one year of water injection (Figure 4b).

[Fig.4]

\section{Discussion on the underlying assumptions}

\subsection{Fluid properties dependence on pressure}

The flow is considered incompressible in Buckley-Leverett theory and the fluids density and viscosity are fixed. However, the pressure varies in a significant range (over time and space) when injecting $\mathrm{CO}_{2}$ (see e.g. Zhou et al. 2008) so that fluid parameters can change over a wide range of values during injection. Please note that the effects of $\mathrm{CO}_{2}$ incompressibility approximation in analytical sharpinterface models have been recently explored by Vilarrasa et al. (2010). They found out that the error in the interface position due to this assumption is rather small when viscous forces dominate.

From a user perspective, only one couple density-viscosity is chosen in the analytical model. Several choices can be done:

- the values for an estimated pressure that would correspond to a maximum or a mean value during both injections $\left(\mathrm{CO}_{2}\right.$ and water), but this requires the use of a pressure estimation model;

- the values at initial pressure (we consider the temperature constant in that paper); this choice was made in section 4.2. These values can easily be computed from tables or formulas, but the viscosity and density may be underestimated, hence influencing the multiphase flow processes. 
As the second choice seems more convenient, we explore in the following the influence on the results of such an assumption. To validate the analytical model on that point, i.e. to explore the effects of the spatial and temporal pressure variations, a comparison with numerical simulations that account for these variations is necessary. For this purpose, the multiphase fluid flow transport code TOUGH2 (Pruess et al. 1999) including the EOS module $\mathrm{ECO}_{2} \mathrm{~N}$ (Pruess 2005) and a hysteresis module (see Doughty 2009) is used. In this last module, Land's trapping model is considered with hysteretic characteristic functions derived from van Genuchten's capillary pressure function (van Genuchten 1980) and based on Lenhard and Parker's relative permeabilities (Lenhard and Parker 1987). For a proper comparison, please note that, in the numerical simulations:

- the geometry and properties are the same than in the reference test case;

- the solubility of components in both phases is not considered;

- the gravity is neglected in the numerical simulations (1D horizontal mesh);

- the salinity is set to zero;

- the capillary pressure is neglected;

- the flow is isothermal.

To investigate the influence of pressure variations (across space and time) a range of numerical simulations are carried out given different injection conditions, i.e. compressibility conditions: (1) 95 and $60 \mathrm{kt} / \mathrm{y}$ for $\mathrm{CO}_{2}$ and water respectively ("low" injection rates); (2) 250 and $160 \mathrm{kt} / \mathrm{y}$ ("moderate" injection rates) and (3) 500 and $315 \mathrm{kt} / \mathrm{y}$ ("high" injection rates).

The saturation profiles after four months of water injection and the mobile gas mass fraction are compared to the solutions given by the analytical model for a density-viscosity couple corresponding to the initial pressure. The comparison shows very satisfactory match (see Figure 5 and Figure 6); the best fit is obtained logically at low rates when compressibility effects are the less significant (when the pressure is the closest to the initial one); the relatively good match is observed between the profiles even at high rates despite the deviations between densityviscosity values taken in the analytical model and the values computed in the numerical simulations (Figure 7 depicts these deviations just after the end of the $\mathrm{CO}_{2}$ injection). More precisely, increasing the pressure does not result in strong 
differences for the imbibition front positions and mobile gas mass fraction while the gas advancement front seems more sensitive to those pressure effects.

[Fig.5]

[Fig.6]

[Fig.7]

In order to explain the results obtained, we explore the respective influence of density and viscosity changes (by decoupling them). Figure 8 depicts the analytical solution (for the case with "high" injection rates) with gas properties taken at initial aquifer pressure (120 bars, see Table 1), and with gas density and viscosity taken alternatively and then together at high pressure $\left(180 \mathrm{bars}, \mu_{\mathrm{g}}=\right.$ $7.04 \cdot 10^{-5}$ Pa. s, $\left.\rho_{\mathrm{g}}=790 \mathrm{~kg} . \mathrm{m}^{-3}\right)$.

Keeping the same mass injection rate, changes in gas density induce changes in gas injection volumetric rate; then, at a given time and in the drainage zone, the saturation (and notably the leading one) will be closer to the injection well for higher values of density. However, this statement does not hold for the imbibition front: the saturation propagation in the drainage zones being more rapid when density is low, the water advancement front collide with higher gas saturations. However, the velocity of this front depends on the reached saturation so that it is higher when the saturation is lower. The imbibition front will therefore reach a higher distance for a higher density value (see on Figure 8). According to equation (18), mobile gas mass fraction (as a function of the saturation reached or as a function of the dimensionless time) does not depend on density; however, coming back to dimensioned time requires gas density (through the injection rates ratio). Concretely, the mobile gas mass fraction left after a given water injection period is less significant for higher density values (see on Figure 8).

Gas viscosity plays a role in the gas fractional flow as a gas with a lower viscosity flows more easily within water (i.e. fractional flow is higher). The velocity of the gas advancement front is higher for lower viscosity values (see on Figure 8). For the same quantity of gas injected (changing viscosity has no influence on the volumetric injection rates), the saturation at a given distance of the well is then lower with a lower viscosity (it is true for the whole profile except close to the advancement gas front). The imbibition front will be faster when the gas is less 
viscous (see on Figure 8). In addition, Figure 8 shows larger trapped quantities for lower viscosity values.

According to this discussion, defining constant viscosity and density value at initial conditions may lead to an overestimation of the leading drainage front. However, regarding the imbibition front and above all mobile gas mass fraction, viscosity and density-related processes act to compensate each other leading to little differences even for relatively large pressure differences.

[Fig.8]

\subsection{Influence of the capillary pressure}

Including capillary effects in equation (1) amounts to add a diffusion-like term (see e.g. Pinder and Celia 2006). Practically, this will induce changes in the flow but also a smoothing of the sharp fronts (i.e. $\mathrm{CO}_{2}$ and injected water fronts). Integrating the capillary term in the fractional flow formula gives:

$$
\text { (19) } f_{g}=\frac{1-\frac{k \lambda_{l} A}{q_{t o t}} \frac{\partial P_{c}}{\partial r}}{1+\frac{\lambda_{l}}{\lambda_{g}}}
$$

with $P_{c}=P_{g}-P_{l}$.

$\frac{\partial P_{c}}{\partial r}$, as the product of $\frac{\partial P_{c}}{\partial S_{g}}$ and $\frac{\partial S_{g}}{\partial r}$, is negative in the drainage part of the plume and positive in the imbibition zone, which means that capillary effects will lead to a gas flow increase in the drainage part and a reduction in the wetting one. In literature, these effects are mostly neglected when advective effects are enough significant so that the difference in capillary pressure during saturation evolution is usually considered low compared to pressure gradients. Errors due to this simplification will be maximized for high saturation gradient (Juanes and Patzek 2002): at both fronts level, there is a capillary fringe where the differences in saturation profile with or without capillary effects get more significant; the fronts are then smoother with capillary effects. In particular, the smoothing of the imbibition front renders questionable the instantaneous trapping hypothesis explained in section 3.2 that leads to a more sharpened front.

To examine the effects of neglecting capillary pressure and of the additional instantaneous trapping approximation, we run numerical simulations of the application case including capillary pressure and for different injecting rates (the 
same than for the previous section). In the code used, the capillary pressure evolution is derived from van Genuchten's capillary pressure function in order to take into account hysteresis effects. The chosen capillary strength is 1 bar with a van Genuchten $m$ equal to 0.457 .

Figure 9 and Figure 10 confirm the more significant influence of capillary effects for lower rates. The gas saturation profiles show that the analytical model underestimates the position of the leading $\mathrm{CO}_{2}$ and water advancement fronts. Quantitatively, the no-capillary pressure and instantaneous trapping approximations lead to more significant differences than the incompressible flow one. However, $\mathrm{CO}_{2}$ injection operations and possible remediation measures in case of abnormal behaviour of the storage complex mostly imply moderate to high rates (i.e. industrial rates of the same order of magnitude of other underground activities such as deep geothermal activities) and hence, the simplifications made do not affect considerably the results, especially the trapped quantity evolution (Figure 10).

[Fig.9]

[Fig.10]

\section{Summary and further works}

An analytical Buckley-Leverett model has been set-up for $\mathrm{CO}_{2}$ injection followed by a brine injection in a radially symmetric geometry. An analytical solution for saturation profile has been derived, which renders possible the assessment of the mobile gas remaining in the system as a function of the brine injection time. It then provides the quantity and the location of the mobile gas, which are both of primary importance when dealing with CCS safety.

This assessment method is flexible to the chosen trapping and hysteresis models. It is rather simple and quick since, concerning the hysteresis model, it only requires the formula of the first drainage relative permeabilities functions. The solutions indeed do not depend on capillary pressure curves neither on relative permeabilities for imbibition and for the other cycles. This simplicity allows the implementation in spreadsheet type software.

The analytical solution is based on a range of simplifications and assumptions whose influence has been explored by means of the comparison with numerical 
simulations. This comparison showed that the effects of the incompressible flow simplification are low especially concerning the evolution of the mobile gas quantity; the capillary pressure influence logically decreases when injection rates increase and becomes negligible as soon as industrial rates are concerned. Moreover, the instantaneous trapping approximation does not have major consequences on the results.

A second trapping mechanism plays an important role, namely the solubility trapping ( $\mathrm{CO}_{2}$ dissolution) and acts as an additional safety guaranty against gaseous $\mathrm{CO}_{2}$ leakage (e.g. Ennis-King and Paterson 2005). Further developments of the analytical solution will then be focused on the integration of mutual solubility between phases.

\section{Acknowledgements}

The authors want to thank Arnaud Réveillère for his help to this work. This study has been supported by the BRGM's Research project $\mathrm{CO}_{2}$ risks Management tools integrated in the Directorate of Research project CSCR03. 


\section{Reference list}

Bachu, S., Gunther, W.D., Perkins, E.H.: Aquifer disposal ofCO 2 : hydrodynamic and mineral trapping. Energy Conv. Manag. 35(4), 269279 (1994)

Bachu, S.: Sequestration of $\mathrm{CO}_{2}$ in geological media in response to climate change: road map for site selection using the transform of the geological space into $\mathrm{CO}_{2}$ phase space. Energy Convers. Manag. 43, 87102 (2002)

Bear, J.: Dynamics of fluids in porous media. Elsevier, New York (1972)

Brooks, R. H., Corey, A.T.: Hydraulic properties of porous media. J. Irrig. Drain. Div. Am. Soc. Civil Eng. 92, 6188 (1966)

Buckley, S.E., Leverett, M.C.:Mechanism of fluid displacements in sands. Trans. AIME 146, 107116 (1942)

Carlson, F.M.: Simulation of relative permeability hysteresis to the nonwetting phase. SPE 10157, Proceedings of the SPE Annual Technical Conference and Exhibition, San Antonio, TX, USA, October 5-7 (1981)

de Gennes, P.G., Brochard-Wyart, F., Quere, D.: Capillarity and Wetting Phenomena Drops, Bubbles, Pearls, Waves. Springer-Verlag, New York (2003)

Dentz M., Tartakovsky D.M.: Abrupt-Interface Solution for Carbon Dioxide Injection into Porous Media. Transp. Porous Med. 79, 1527 (2009)

Doughty C.: Modeling geologic storage of carbon dioxide: Comparison of non-hysteretic and hysteretic characteristic curves. Energy Convers. Manag. 48, 17681781 (2007)

Doughty, C.: User's Guide for Hysteretic Capillary Pressure and relative Permeability Functions in iTOUGH2. Report LBNL-2483E. Lawrence Berkeley National Laboratory, Berkeley, CA, USA (2009)

EC (European Commission): Directive 2009/31/EC of the European Parliament and of the Council of 23 April 2009 on the geological storage of carbon dioxide and amending Council Directive 85/337/EEC, European Parliament and Council Directives 2000/60/EC, 2001/80/EC, 2004/35/EC, 2006/12,EC, 2008/1/EC and Regulation (EC) No 1013/2006 (2009).

Ennis-King, J., Paterson, L.: Role of convective mixing in the long-term storage of carbon dioxide in deep saline formations. Soc. Pet. Eng. J. 10(3), 349356 (2005)

Esposito A., Benson S.: Remediation of Possible Leakage from Geologic $\mathrm{CO}_{2}$ Storage Reservoirs into Groundwater Aquifers. Proceedings of the Greenhouse Gas Control Technologies - 10th International Conference, Amsterdam, The Netherlands. Sept. 19-23 2010 (2010)

Furati, K. M.: Effects of relative permeability history dependence on two-phase flow in porous media. Transp. Porous Med. 28, 181203 (1997)

Gasda S.E., Nordbotten J.M., Celia M.A.: Vertical equilibrium with sub-scale analytical methods for geological $\mathrm{CO}_{2}$ sequestration. Comput. Geosci. 13, 469481 (2009)

Gunter, W.D., Wiwchar, B., Perkins, E.H.: Aquifer disposal of $\mathrm{CO}_{2}$-rich greenhouse gases: Extension of the time scale of experiment for $\mathrm{CO}_{2}$-sequestering reactions by geochemical modeling. Miner. Pet. 59(1-2), 121140 (1997) 
Hesse, M. A., Tchelepi, H. A. \& Orr Jr, F. M.: Scaling analysis of the migration of $\mathrm{CO}_{2}$ in saline aquifers. In SPE Annual Technical Conference and Exhibition (SPE 102796), San Antonio, TX (2006)

Hesse, M. A., Tchelepi, H. A., Cantwell, B. J. \&Orr Jr, F. M.: Gravity currents in horizontal porous layers: transition from early to late self-similarity. J. Fluid Mech. 577, 363383 (2007)

IEA Greenhouse Gas R\&D Programme (IEA GHG): Role of Risk Assessment in Regulatory Framework for Geological Storage of $\mathrm{CO}_{2}$ : Feedback from Regulators and Implementers. Report 2007/2, 88 p. (2007)

Intergovernmental Panel on Climate Change (IPCC): Special Report on Carbon Dioxide Capture and Storage. Metz, B., Davidson, O., de Connick, H., Loos, M., Meyer, L. (Eds.), Cambridge University Press, New York (2005)

Juanes, R., MacMinn, C. W.: Upscaling of capillary trapping under gravity override: application to $\mathrm{CO}_{2}$ sequestration in aquifers. In SPE/DOE Symposium on Improved Oil Recovery (SPE 113496), Tulsa, OK, USA (2008)

Juanes, R., MacMinn, C.W., Szulczewski, M.L.: The Footprint of the $\mathrm{CO}_{2}$ Plume during Carbon Dioxide Storage in Saline Aquifers: Storage Efficiency for Capillary Trapping at the Basin Scale. Transp. Porous Med. 82, 1930 (2010)

Juanes, R., Patzek, T.W.: Multiscale finite element methods for miscible and immiscible flow in porous media, In CD Proceedings of the International Groundwater Symposium of the IAHR, Berkeley, California, March 2002 (2002)

Juanes, R., Spiteri, E.J., Orr, Jr. F.M., Blunt, M.J.: Impact of relative permeability hysteresis on geological $\mathrm{CO}_{2}$ storage. Water Resour. Res. 42, W12418 (2006). doi:10.1029/2005WR004806 Kochina, I.N., Mikhailov, N.N., Filinov, M.V.: Groundwater mound damping. Int. J. Eng. Sci. 21, 413421 (1983)

Land, C.S.: Calculation of imbibition relative permeability for two- and three-phase flow from rock properties. SPE J. 8, 149156 (1968)

Lax, P.D.: The formation and decay of shock waves. Amer. Math. Monthly 79(3), 227241 (1972)

Lenhard, R.J., Parker, J.C.: A model for hysteretic constitutive relations governing multiphase flow - 2. Permeability-saturation relations. Water Resour. Res. 23(12), 21972205 (1987)

Lenormand, R., Zarcone, C., Sarr, A.: Mechanisms of the displacement of one fluid by another in a network of capillary ducts. J. Fluid Mech. 135, 123132 (1983)

MacMinn C.W., Szulczewski M.L., Juanes R.: $\mathrm{CO}_{2}$ migration in saline aquifers. Part 1: Capillary trapping under slope and groundwater flow. J Fluid Mech. 662, 329351 (2010)

Manceau J.C., Réveillère A., Rohmer J.: Forcing gaseous $\mathrm{CO}_{2}$ trapping as a corrective technique in the case of abnormal behavior of a deep saline aquifer storage. Proceedings of the Greenhouse Gas Control Technologies - 10th International Conference, Amsterdam, The Netherlands. Sept. 19-23 2010 (2010)

McWorther D.B., Sunada D.K.: Exact integral solutions for two-phase flow. Water Resour. Res. 26(3), 399413 (1990) 
Medeiros H.B., Marchesin D., PAES LEME P.J.: Hysteresis in two-phase flow: a simple mathematical model. Comp. Appl. Math. 17(1), 8199 (1998)

Müller, N., Supercritical $\mathrm{CO}_{2}$-brine relative permeability experiments in reservoir rocks Literature review and recommendations. Transp. Porous Med. 87, 367383 (2011)

Nghiem, L., Yang, C., Shrivastava, V., Kohse, B., Hassam, M., Card, C.: Risk mitigation trough the optimization of residual gas and solubility trapping for $\mathrm{CO}_{2}$ Storage in saline aquifers. Energy Procedia 1, 30153022 (2009)

Noh, M., Lake, L., Bryant, S., Araque-Martinez, A.: Implications of coupling fractional flow and geochemistry for $\mathrm{CO}_{2}$ injection in aquifers. SPE REE J. 10(4), 406414 (2007)

Nordbotten, J. M., Celia, M. A., Bachu, S.: Injection and storage of $\mathrm{CO}_{2}$ in deep saline aquifers: analytical solution for $\mathrm{CO}_{2}$ plume evolution during injection. Transp. Porous Med. 58(3), 339360 (2005)

Nordbotten, J. M., Celia, M. A.: Similarity solutions for fluid injection into confined aquifers. J. Fluid Mech. 561, 307327 (2006)

Parker, J.C., Lenhard, R.J.: A model for hysteretic constitutive relations governing multiphase flow - 1. Saturation-pressure relations. Water Resour. Res. 23(12), 21872196 (1987)

Pinder, G.F., Celia, M.A.: Subsurface Hydrology. John Wiley \& Sons Inc., Hoboken, New Jersey (2006)

Pruess, K., Oldenburg, C.M., Moridis, G.: TOUGH2 User's Guide, Version 2.0. Report LBNL43134. Lawrence Berkeley National Laboratory, Berkeley, CA, USA (1999)

Pruess, K., Spycher, N.: $\mathrm{ECO}_{2} \mathrm{~N}-$ A fluid property module for the TOUGH2 code for studies of $\mathrm{CO}_{2}$ storage in saline aquifers. Energy Convers. Manag. 48, 17611767 (2007)

Pruess, K.: $\mathrm{ECO}_{2} \mathrm{~N}$ : A TOUGH2 Fluid Property Module for Mixtures of Water, $\mathrm{NaCl}$, and $\mathrm{CO}_{2}$. Report LBNL-57952. Lawrence Berkeley National Laboratory, Berkeley, CA, USA (2005)

Qi, R., LaForce, T.C., Blunt, M.J.: Design of carbon dioxide storage in aquifers. Int. J. Greenh.

Gas Control 3, 195205 (2009)

Smoller, J.: Shock waves and reaction-diffusion equations. Springer-Verlag, New York (1994)

Spiteri, E.J., Juanes, R., Blunt, M.J., Orr Jr., F.M.: A new model of trapping and relative permeability hysteresis for all wettability characteristics. SPE J. 13(3), 277288 (2008).

doi:10.2118/96448-PA

Suicmez, V.S., Piri, M., Blunt, M.J.: Effects of wettability and pore-level displacement on hydrocarbon trapping. Advances Water Resour. 31, 503512 (2008)

Valvatne P.H.: Predictive pore-scale modeling of multiphase flow. A dissertation submitted to the Department of Earth Science and Engineering of Imperial College London in partial fulfillment of the requirements for the degree of Doctor of Philosophy (2004)

van Genuchten, M.T.: A closed-form equation for predicting the hydraulic conductivity of unsaturated soils. Soil Sci. Soc. Am. J. 44, 892898 (1980)

van Kats F.M., van Duijn C.J.: A mathematical model for hysteretic two-phase flow in porous media. Transp. Porous Med. 43, 239263 (2001) 
Vilarassa, V., Bolster, D., Dentz, M., Olivella, S., Carrera, J.: Effects of $\mathrm{CO}_{2}$ compressibility on $\mathrm{CO}_{2}$ storage in deep saline aquifers. Transp. Porous Med. 85, 619639 (2010)

Welge H.J.: A simplified method for computing oil recovery by gas or water drive. Petrol. Trans. AIME 195, 9198 (1952)

Yortsos Y.C.: A theoretical analysis of vertical flow equilibrium. Transp. Porous Med. 18, 107129 (1995)

Zeidouni M., Pooladi-Darvish M., Keith D.: Analytical solution to evaluate salt precipitation during $\mathrm{CO}_{2}$ injection in saline aquifers. Int. J. Greenh. Gas Control 3, 600611 (2009)

Zhou, Q., Birkholzer, J.T., Tsang, C.F., Rutqvist, J.: A method for quick assessment of $\mathrm{CO}_{2}$ storage capacity in closed and semi-closed saline formations. Int. J. Greenh. Gas Control 2(4), 626639 (2008) 


\section{Appendix: nomenclature}

\begin{tabular}{|c|c|}
\hline$q$ & Volumetric flow rate, $m^{3} \cdot s^{-1}$ \\
\hline$A$ & Area, $m^{2}$ \\
\hline$S$ & Saturation \\
\hline$f$ & Volumetric fractional flow \\
\hline$h$ & Aquifer height, $m$ \\
\hline$T$ & Injection time, $s$ \\
\hline$V$ & Volume, $m^{3}$ \\
\hline$f r$ & Mass fraction \\
\hline$k$ & Permeability \\
\hline$Q$ & Injection volumetric flow, $m^{3} \cdot s^{-1}$ \\
\hline$\mu$ & Viscosity, $P$ a.s \\
\hline$\lambda$ & Mobility \\
\hline$\varphi$ & Porosity \\
\hline$r$ & Radius, $m$ \\
\hline$\xi$ & Dimensionless radius \\
\hline$\zeta$ & Similarity variable \\
\hline$t$ & Time, $s$ \\
\hline$\tau$ & Dimensionless time \\
\hline$P$ & Pressure, $P a$ \\
\hline$\rho$ & Density, $k g \cdot m^{-3}$ \\
\hline \multicolumn{2}{|l|}{ Index } \\
\hline$g$ & Gas phase \\
\hline$l$ & Liquid phase \\
\hline$\Delta$ & Flow reversal \\
\hline$r$ & Residual \\
\hline $\max$ & Maximum \\
\hline rel & Relative \\
\hline+ & Upstream \\
\hline- & Downstream \\
\hline shocki & Shock no.i \\
\hline * & Chosen (given) \\
\hline
\end{tabular}



collision Collision
freeg Mobile gas
C
Capillary 


\section{Figures}

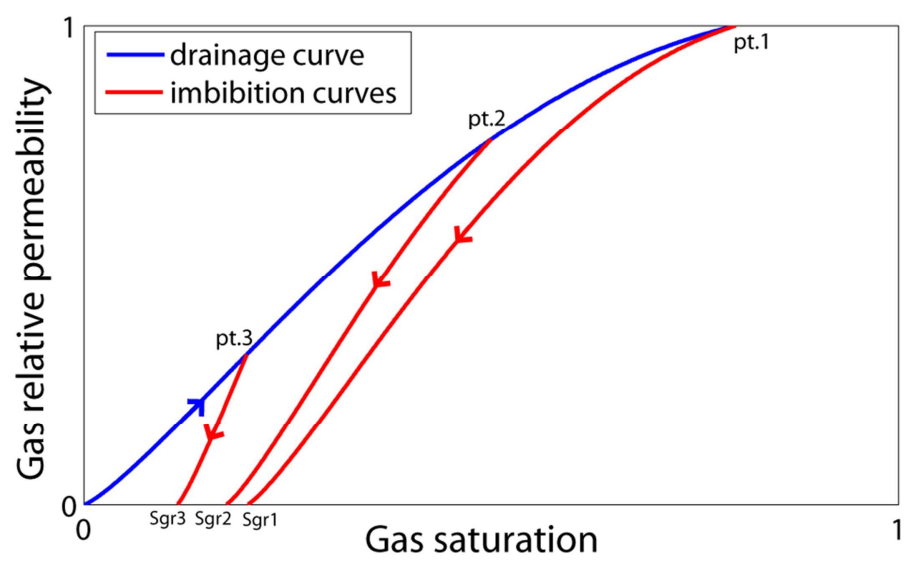

Figure 1: Evolution of the gas relative permeability including hysteresis effects: in drainage phase (increasing of gas saturation), the gas relative permeability curve is the blue curve. According to the turning point between drainage and imbibition (here pt.1, pt.2 or pt.3), the gas relative permeability curve for imbibition process is different. Please note that the residual saturations (Sgr1, Sgr2 and Sgr3) depend on the turning points and are computed with a trapping model. The models used and the associated parameters are the ones used later on in this paper (in section 4.2)

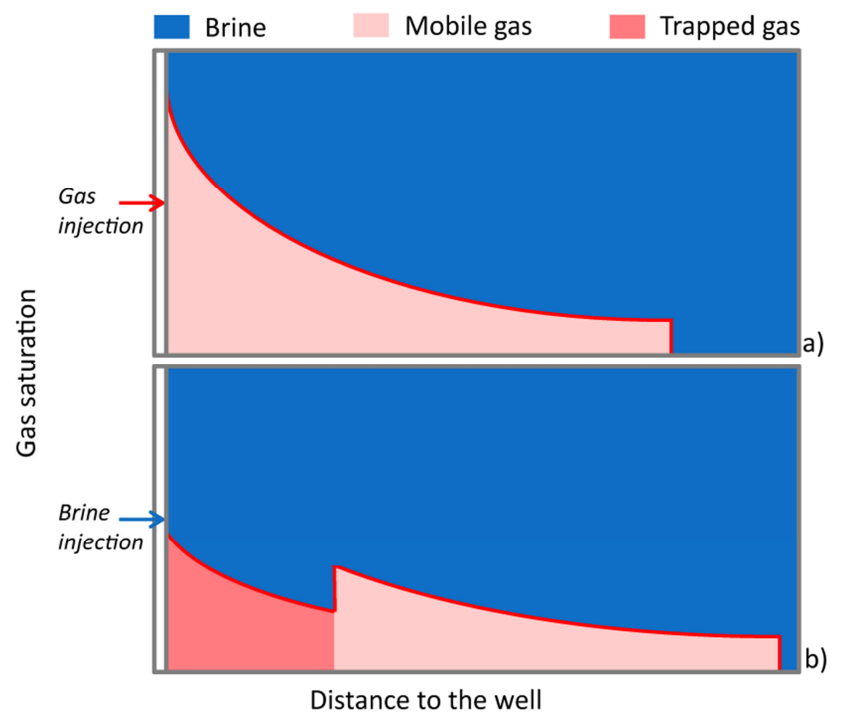

Figure 2: Conceptual layout of the gas saturation evolution a) during gas injection (phase I) and b) during the following brine injection (phase II) 


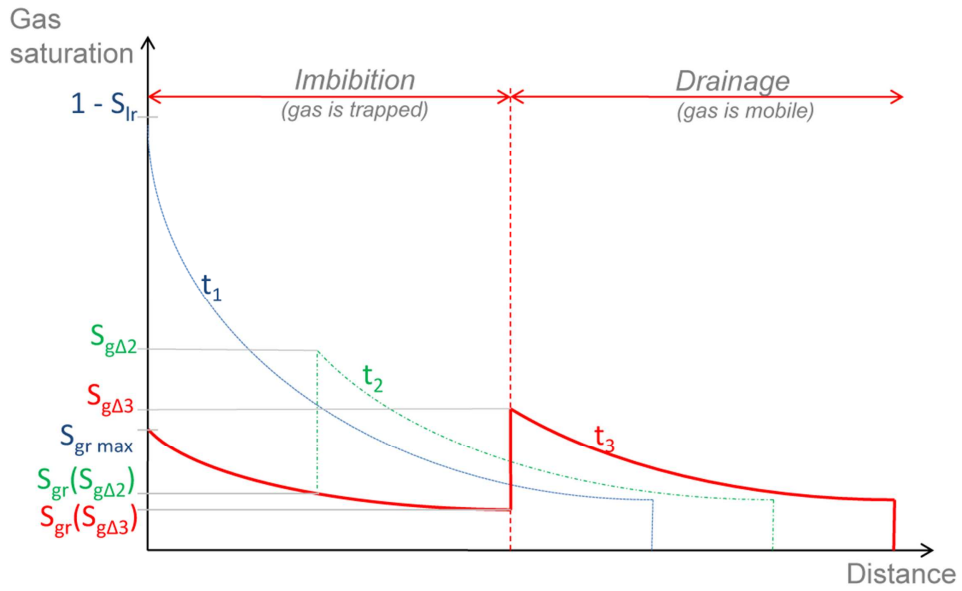

Figure 3: Gas saturation profile at different instant times: $\mathrm{t}_{1}$ (end of the $\mathrm{CO}_{2}$ injection period), $\mathrm{t}_{2}$ and $t_{3}$ (after given times of brine injection) so that $t_{1}<t_{2}<t_{3}$. Upward to the brine advancement front, the profile consists in saturation waves still evolving in the drainage phase. Downward to the imbibition front the profile is made of the residual saturations calculated from the saturation reached at earlier time - e.g. at $\mathrm{t}_{2}$, the brine advancement front has reached the saturation corresponding to a residual saturation of
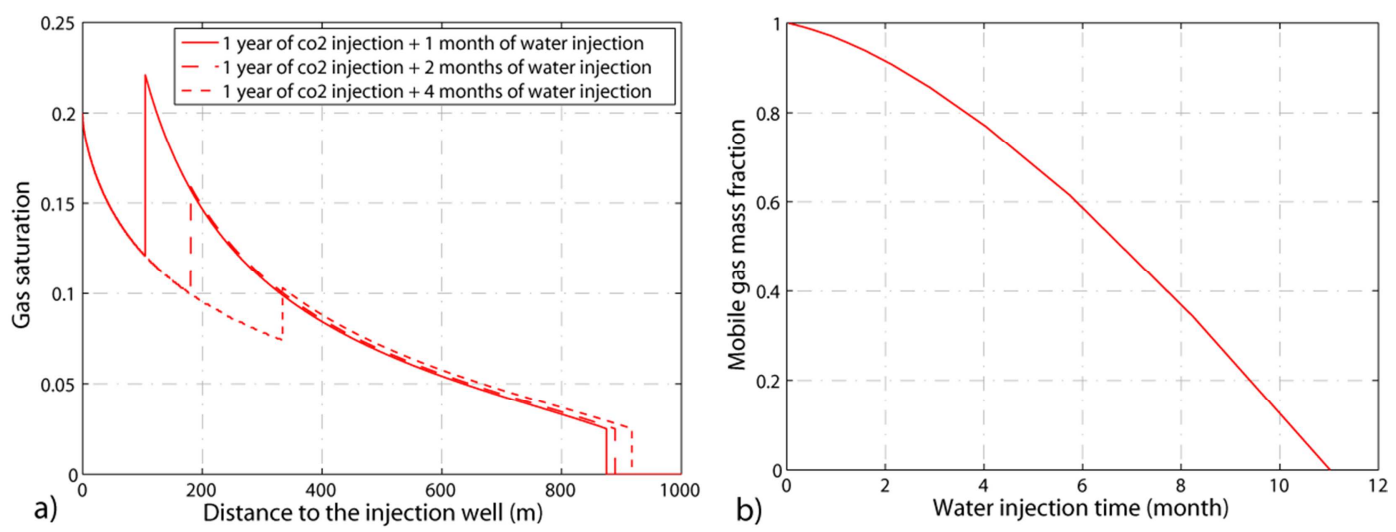

Figure 4: Analytical solution a) for the gas saturation profile for three different brine injection periods following one year of gas injection and b) for mass fraction of mobile gas remaining as a function of brine injection time 


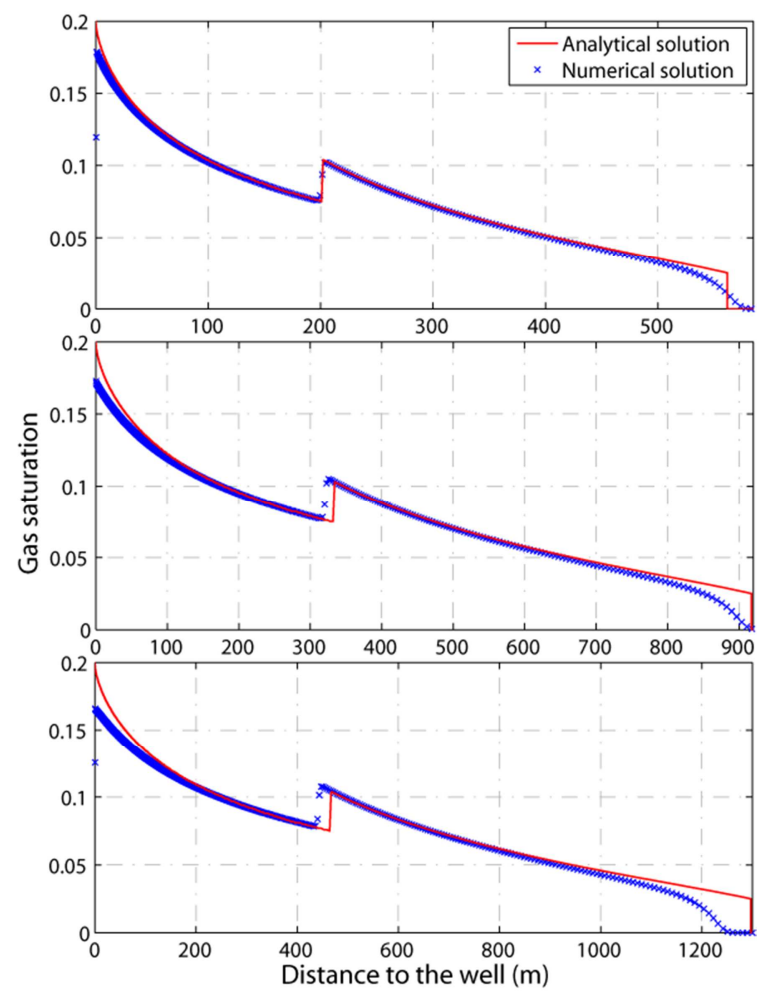

Figure 5: Comparison analytical-numerical gas saturation results for low (up), medium (middle) and high (down) injection rates (note the different horizontal axis scale). The dissolution process is removed in the numerical simulator

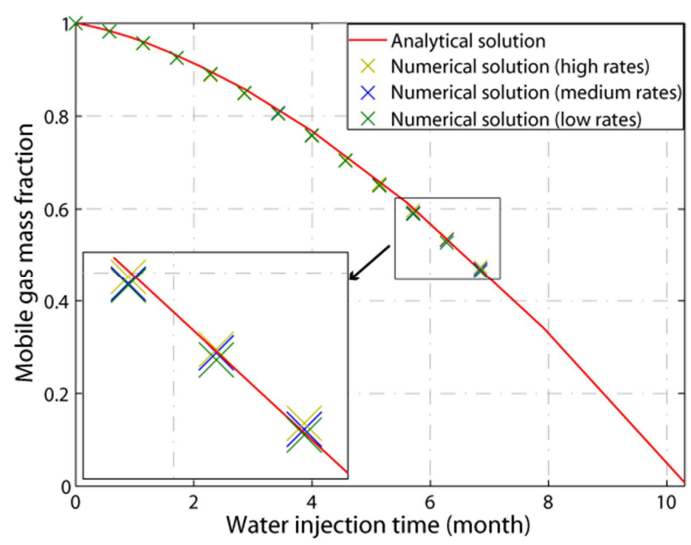

Figure 6: Analytical and numerical results concerning the mobile gas mass fraction evolution for different injection rates. The injection rates ratio being the same for the rates used in the numerical simulations, the analytical solutions for mass fraction evolution of mobile gas are the same. The dissolution process is removed in the numerical simulator 

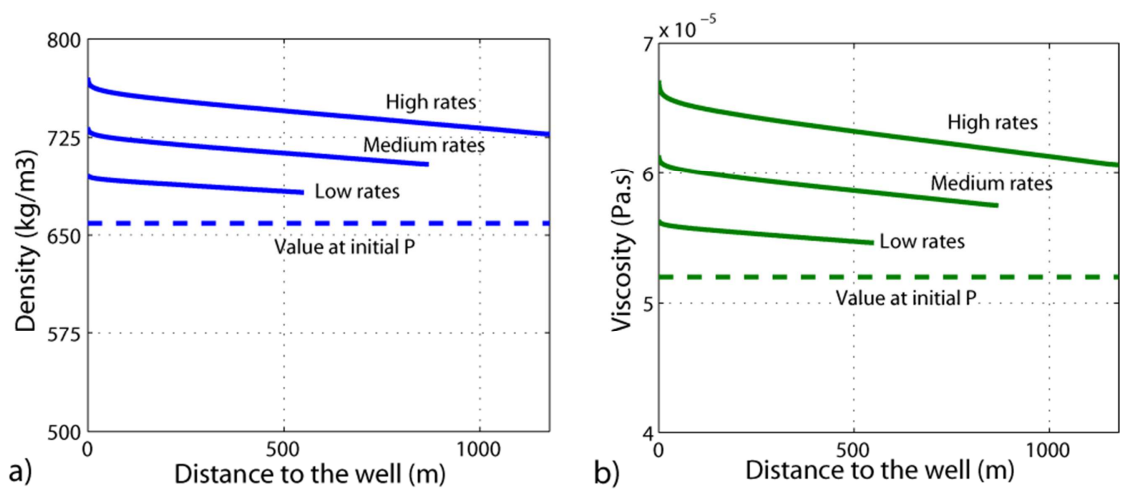

Figure 7: Deviations between (a) density and (b) viscosity values taken in the analytical model and the values computed in the numerical simulations after 1 year of $\mathrm{CO}_{2}$ injection (at three different rates)
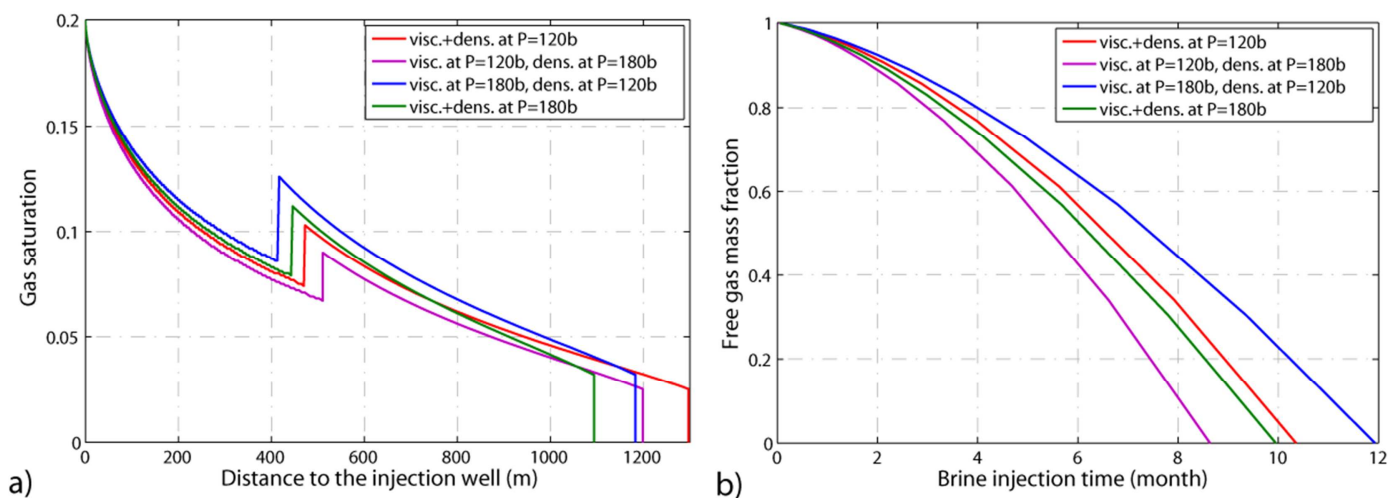

Figure 8: Effects of viscosity and density changes on the analytical solution - a) saturation profile,

b) mobile gas mass fraction evolution 

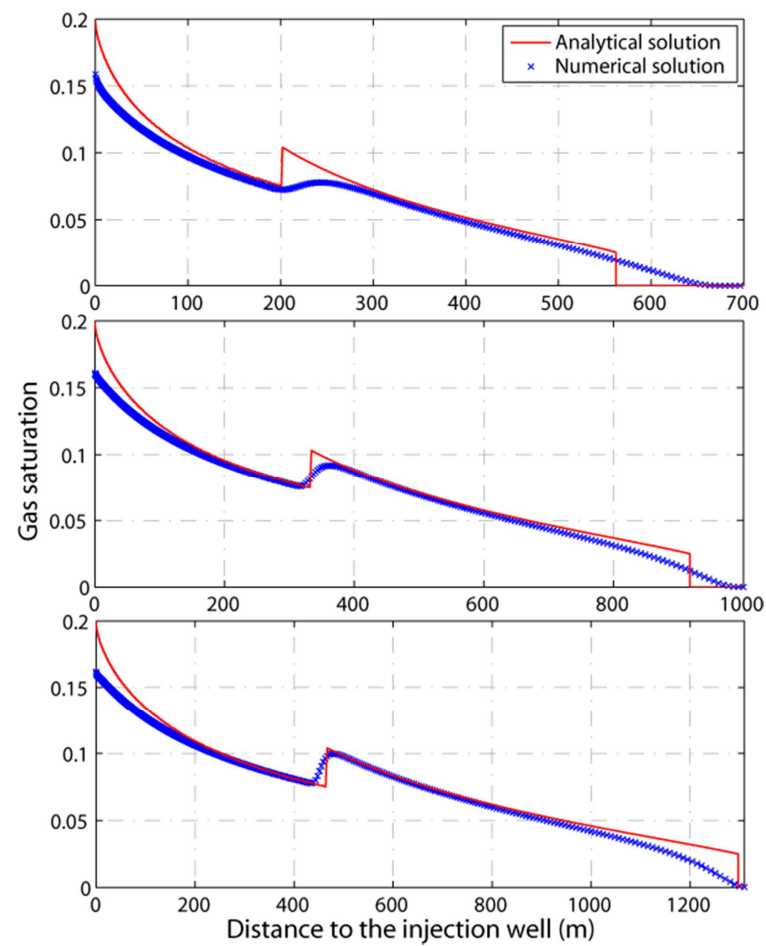

Figure 9: Comparison analytical-numerical (with capillary effects) gas saturation results for low (up), medium (middle) and high (down) injection rates (note the different horizontal axis scale). The dissolution process is removed in the numerical simulator

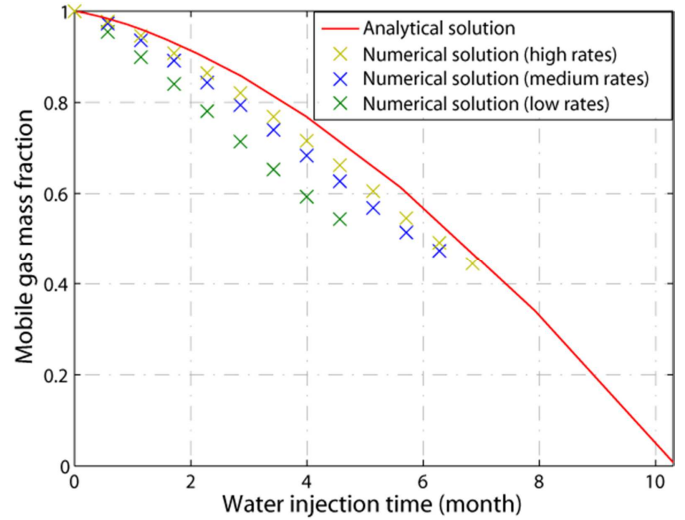

Figure 10: Analytical and numerical (with capillary effects) results concerning the mobile gas mass fraction evolution for different injection rates. The dissolution process is removed in the numerical simulator 
Table 1: Initial conditions chosen in the simulations

\begin{tabular}{|l|l|}
\hline Initial pressure & $120 \mathrm{bars}$ \\
\hline Initial temperature & $45^{\circ} \mathrm{C}$ \\
\hline Porosity & 0.12 \\
\hline Initial salinity & $0 \mathrm{~g} . \mathrm{l}^{-1}$ \\
\hline Gas phase density & $659 \mathrm{~kg} \cdot \mathrm{m}^{-3}$ \\
\hline Liquid phase density & $995 \mathrm{~kg} \cdot \mathrm{m}^{-3}$ \\
\hline Gas phase viscosity & $5.2 \cdot 10^{-5} \mathrm{~Pa} . \mathrm{s}$ \\
\hline Liquid phase viscosity & $5.98 \cdot 10^{-4} \mathrm{~Pa} . \mathrm{s}$ \\
\hline
\end{tabular}

Table 2: Input parameters

\begin{tabular}{|l|l|}
\hline van Genuchten $m$ & 0.457 \\
\hline Residual liquid saturation & $S_{l r}=0.2$ \\
\hline Maximum residual gaseous saturation & $S_{\text {grmax }}=0.2$ \\
\hline
\end{tabular}

The original version is available at www.springerlink.com 